\title{
A TRAJETÓRIA DAS CERVEJARIAS ARTESANAIS BRASILEIRAS EM BUSCA DE LEGITIMAÇÃO E INSTITUCIONALIZAÇÃO: UMA ANÁLISE A PẢRTIR DE SUAS PRÁTICAS ESTRATÉGICAS DISCURSIVAS
}

Data de submissão: 05/05/2014 Aceite: 29/12/2016

\author{
Adriano Olímpio Tonelli ${ }^{1}$ \\ Alex Fernando Borges ${ }^{2}$ \\ Mozar José de Brito 3 \\ André Luiz Zambalde ${ }^{4}$
}

\section{RESUMO}

O objetivo deste trabalho consistiu em identificar e compreender as práticas estratégicas discursivas voltadas para a legitimação e institucionalização da indústria brasileira de cervejas artesanais. Para tanto, procuramos fundamentar, teoricamente, a relação entre estratégia como prática discursiva e institucionalismo e, metodologicamente, a abordagem da análise crítica do discurso. Verificou-se que a indústria brasileira de cervejas artesanais encontra-se em um processo de institucionalização junto ao ambiente e de legitimação junto aos consumidores, através de práticas discursivas que revelam disputas de poder com as grandes cervejarias. Nesse sentido, a própria produção de cervejas artesanais pode ser vista como uma ideologia, caracterizada a partir de um forte posicionamento de oposição, enfrentamento e resistência a práticas já institucionalizadas no mercado cervejeiro brasileiro. Sendo assim, revelam-se possibilidades de construção de um campo próprio, estruturado por meio de estratégias discursivas que podem, no limite, levar a uma emancipação em relação ao ambiente das grandes cervejarias.

Palavras-chave: Estratégia como Prática; Institucionalismo; Análise Crítica do Discurso.

\footnotetext{
1 Possui graduação em Bacharelado em ciência da computação pela Universidade Federal de Lavras, UFLA, mestrado em Administração pela UFLA e doutorado em Administração pela UFLA. Formiga-MG. Brasil. E-mail: adriano.tonelli@ifmg.edu.br

2 Possui graduação em Administração pela Universidade Federal de Lavras, UFLA, mestrado em Administração pela UFLA e doutorado em Administração pela UFLA. Ituiutaba-MG. Brasil. E-mail: alexborges@pontal.ufu.br

3 Graduação em Administração Rural pela Universidade Federal de Lavras, UFLA, mestrado em Administração Rural pela UFLA e doutorado em Administração pela Universidade de São Paulo, USP. Lavras-MG. Brasil. E-mail: mozarjdb@dae.ufla.br

4 Possui graduação em Engenharia Elétrica Telecomunicações pelo Instituto Nacional de Telecomunicações de Sta Rita Sapucai, INATEL, mestrado em Engenharia Elétrica pela Universidade Federal de Itajubá, UNIFEl e doutorado em Engenharia de Sistemas e Computação pela Universidade Federal do Rio de Janeiro, UFR. Lavras-MG. Brasil. E-mail: zamba@dcc.ufla.br
} 


\section{INTRODUÇÃO}

Os estudos em estratégia têm se mostrado uma área fértil e profícua para a análise organizacional. Com efeito, investigações envolvendo essa temática têm contribuído para o desenvolvimento das ciências administrativas e para o aprimoramento da prática empresarial ao longo dos últimos 50 anos. Nesse sentido, verificam-se avanços importantes em termos epistemológicos, teóricos e metodológicos, os quais possibilitam a configuração de um campo relevante para o desenvolvimento de pesquisas em Administração.

Não obstante, um olhar mais criterioso para o campo da estratégia permite observar que existem algumas limitações e lacunas que, na atualidade, têm sido tratadas a partir da convergência dos estudos em estratégia com a teoria da prática (JARZABKOWSKI; SPEE, 2009; VAARA; WHITTINGTON, 2012; VALADÃO; SILVA, 2012).

Difundida a partir do trabalho de diversos sociólogos e filósofos, a teoria da prática se mostra como alternativa promissora para a compreensão das estratégias nas organizações (GOLSORKHI et al., 2010; FELDMAN; ORLIKOWSKI, 2011). Essa abordagem se distancia de pressupostos tradicionais da administração estratégia ao considerar o que os membros da organização realmente fazem e colocar a dualidade entre a ação estratégica e as estruturas sociais no centro das explicações do fenômeno da estratégia (WHITTINGTON, 2012; Jarzabkowski, 2004).

Diferentes possibilidades teóricas e metodológicas podem ser exploradas ao se considerar o enfoque da prática sobre os estudos em estratégia. Em especial, perspectivas emergentes consideram a associação da teoria da prática com o institucionalismo (Whittington, 2006; Vaara; Whittington, 2012) e com a virada discursiva nos estudos organizacionais (LECLERCQ-VANDELANNOITTE, 2011). Na medida em que se considera uma dualidade entre ação e estrutura, abrem-se possibilidades para uma renovação do institucionalismo no sentido de se explicar como determinadas lógicas institucionais são criadas, reforçadas e revertidas por ações ao longo do tempo (Lok; De Rond, 2012; SMETS; MORRIS; GREENWOOD, 2012). Da mesma forma, abre-se espaço para considerar uma associação entre discursos, ação e poder, de modo a considerar o papel das práticas discursivas sobre o fazer estratégia, sobre as lógicas institucionais e sobre as relações de poder existentes em um dado campo (LECLERCQ-VANDELANNOITTE, 2011; Foucault, 2010).

Acredita-se que o referido diálogo entre as abordagens mencionadas abra espaço para a construção de abordagens alternativas para o estudo da estratégia, em contextos marcados por ideologias, disputas de poder e busca de legitimação, a exemplo do caso da indústria de cervejas artesanais no Brasil. Trabalhos prévios, tais como Kalnin, Casarotto Filho e Castro (2002), Lamertz, Heugens e Calmet (2005), Ferreira et al. (2011), Flach (2012) e Moreira et al. (2013), investigam a indústria de cervejas artesanais, contemplando aspectos como o mercado, o consumo, as tecnologias e técnicas de produção, as práticas de gestão e as estratégias de organizações do setor. Não obstante, uma análise mais minuciosa da literatura permite constatar certa carência de estudos que abordam o processo de institucionalização, a busca de legitimidade no setor de bebidas e os conflitos das cervejarias artesanais com lógicas institucionais estabelecidas pelo governo e pelas grandes cervejarias. Diante disso, o objetivo deste trabalho consiste em identificar e compreender as práticas estratégicas discursivas voltadas para a legitimação e institucionalização desse campo organizacional no Brasil. Para tanto, primeiramente, será explorada teoricamente a relação entre estratégia como prática discursiva e institucionalismo. Adicionalmente, será apresentada a abordagem teórico-metodológica da análise crítica do discurso, englobando as práticas discursivas dos diferentes agentes e instituições inseridas nesse campo. Assim, será possível lançar luzes sobre as práticas estratégicas que viabilizam a construção do processo de legitimação e 
institucionalização do campo organizacional da indústria de cervejas artesanais no Brasil, gerando implicações para a teoria e pesquisa em estratégia como prática.

\section{ESTRATÉGIA COMO PRÁTICA E TEORIA INSTITUCIONAL}

O campo de estudos sobre estratégia como prática surge, na década de 1990, buscando um novo olhar sobre o fenômeno da estratégia. Sob esse novo enfoque, tem-se a incorporação dos postulados da chamada teoria da prática. Dessa forma, a pesquisa sobre estratégia como prática promove mudanças ontológicas, epistemológicas, teóricas e metodológicas significativas no campo de estudos sobre administração estratégica (VAARA; WHITTINGTON, 2012).

A abordagem da estratégia como prática reverte o pressuposto de que as estratégias são o que as organizações possuem, passando a enfatizar como a estratégia se constitui como algo que os membros da organização fazem (Whittington, 1996, 2006; Jarzabkowski, 2004; Rasche; Chia, 2009). Essa compreensão admite o papel das práticas sociais dentro do processo de estrategizar, bem como a dualidade entre a ação dos estrategistas e as macroestruturas (RASCHE; CHIA, 2009; CHIA; MACKAY, 2007).

Não obstante, Whittington (2006) e Vaara e Whittington (2012) argumentam que há uma necessidade de maior aprofundamento epistemológico e teórico na pesquisa sobre estratégia como prática, bem como o estabelecimento de relações entre o enfoque da prática e teorias institucionais, valorizando como as atividades são imbricadas em um contexto societal ou macroinstitucional. Tem-se, portanto, a necessidade de articulação entre diferentes níveis de análise, de modo a lançar luzes sobre as especificidades da estratégia em uma perspectiva mais ampla, que envolva de modo simultâneo ações de nível micro e o ambiente institucional (Whittington, 2006; Johnson; Smith; Codling, 2010).

Em meio a diferentes abordagens da teoria institucional, uma concepção alternativa consiste em definir o conceito de instituição como sendo padrões para práticas sociais que: a) são distribuídas ao longo do tempo e do espaço; b) encontram-se rotinizadas e c) são legitimadas em termos de uma lógica institucional. As instituições tomam forma de scripts que são marcados por princípios organizadores compostos de conjuntos particulares de regras, crenças e objetivos práticos (JARZABKOWSKI; MATTHIESEN; VAN DE VEN, 2009). Assim, as instituições possuem uma lógica central, abordam uma série de práticas materiais e simbólicas e fornecem lógica à ação de organizações e indivíduos (JARZABKOWSKI; MATTHIESEN; VAN DE VEN, 2009), algo que se aproxima sobremaneira da concepção de estratégia como prática social.

A relação entre a teoria institucional e o enfoque da teoria da prática permite estabelecer, ainda, uma dualidade entre ação e instituição, delimitada como um processo contínuo, marcado por conceitos centrais (BARLEY; TOLBERT, 1997): a) codificação, em que, a partir da socialização, os agentes internalizam regras e interpretações de comportamentos apropriados a determinados contextos institucionais; b) habilitação de scripts no contexto da ação, seja de forma consciente ou não consciente por parte dos agentes; c) a reflexão e o grau em que o agente revisa ou replica scripts informados por lógicas institucionais. Essa concepção baseia-se na teoria da estruturação exposta por Giddens (1984) e considera a capacidade reflexiva dos agentes que, imersos em situações de mudanças tecnológicas, crises econômicas e outros eventos de crise, estão propensos a refletir e modificar lógicas institucionais por meio de suas ações. A noção de lógicas, portanto, não possui caráter puramente top-down; pessoas em contextos reais e com experiências passadas reproduzem, questionam, combinam e modificam essas lógicas. Esses agentes, por sua vez, engajam-se num processo de bricolagem ou hibridismo, onde diferentes lógicas institucionais são (re)combinadas de acordo com demandas práticas e localizadas (BARLEY; TOLBERT, 1997). 
Trabalhos recentes têm incorporado a perspectiva da prática para analisar a relação entre organizações e instituições. Smets, Morris e Greenwood (2012) mostraram como mudanças institucionais podem emergir de atividades de praticantes que se encontram em situações de conflito com lógicas institucionalizadas. Lok e De Rond (2012) mostram como rupturas em práticas podem resultar de tensões entre scripts institucionalizados e o desempenho de práticas. Em essência, esses estudos mostram que lógicas institucionais e agentes nem sempre coexistem em harmonia, criando condições para o surgimento de conflitos. Já os estudos de Coraiola, Mello e Jacometti (2012) e de Almeida e Sales (2011) exploram, em nível nacional, a relação entre teoria institucional e estratégia como prática, repercutindo algumas das implicações da teoria da estruturação giddensiana na compreensão da relação entre estrutura e agência e na apreensão de como se configuram as interações entre as práticas (em nível micro), sendo estas espaço-temporalmente definidas e situadas, e as lógicas institucionais (em nível macro), em seu papel de influência e de (re)construção dessas práticas e de si próprias. Diante desse contexto de potenciais conflitos, cria-se a oportunidade para investigação das relações entre práticas estratégicas e lógicas institucionais em ambientes marcados por disputas de poder (BOURDIEU, 1990; BOURDIEU; WACQUANT, 1992; NORD, 2005; GOMEZ, 2010), como é o caso da indústria de cervejas artesanais do Brasil.

\section{ESTRATÉGIA COMO PRÁTICA DISCURSIVA}

Para apresentar a perspectiva da estratégia como prática discursiva, parte-se de uma transposição da visão foucaultiana de discurso para o pensamento estratégico, associando esta última com a abordagem das práticas discursivas. Esse movimento, que vem sendo amplamente explorado na literatura sobre estratégia como prática e no âmbito dos estudos organizacionais, sugere que o discurso exibe fortes relações com o poder e produz e medeia os fenômenos estratégicos, organizacionais e sociais (LECLERCQ-VANDELANNOITTE, 2011).

Os discursos são elementos de grande relevância na construção da realidade organizacional e envolvem a produção de textos e narrativas (LECLERCQ-VANDELANNOITTE, 2011). Essa construção, a partir de uma visão foucaultiana, pode ser concebida na medida em que discursos podem ser tanto instrumentos quanto efeitos de poder, tanto obstáculos quanto pontos de partida para estratégias de oposição (Foucault, 2010).

Foucault também introduz a concepção de genealogia, com o intuito de se estabelecer uma abordagem para explicar o controle, a seleção, a classificação e a distribuição da produção de discursos através de relações de poder (LECLERCQ-VANDELANNOITTE, 2011). Na análise genealógica, o surgimento e a transformação de uma prática social são resultantes da transformação de práticas anteriores e rivais entre si, revelando um processo de construção de um complexo dinâmico de práticas sociais (ALLARD-POESI, 2010). Em suma, o discurso não é um meio de representar objetos, mas algo performativo em produzir a verdade assumida como certa de que a organização é separada do ambiente, o que informa o pensamento em administração estratégica (EZZAMEL; WILLMOTT, 2008).

Segundo Allard-Poesi (2010), a aplicação da visão foucaultiana à estratégia como prática abre espaço para se considerar as estratégias como discursos que envolvem um conjunto de ideais e práticas que condicionam os meios de se relacionar e de agir sobre fenômenos particulares. Assim, a estratégia é incorporada nas práticas sociais que atualizam e reproduzem seus discursos, constituindo, desse modo, um sistema de poder-conhecimento.

Paralelamente, Ezzamel e Willmott (2008) defendem que a análise foucaultiana não 
busca apenas capturar e catalogar os detalhes específicos do estrategizar (como estrategistas pensam, falam, refletem, agem, interagem, emocionam-se, embelezam-se e politizam-se). Em vez disso, ela é preocupada com a apreciação de como a estratégia, como uma prática discursiva, opera para construir o mundo (instrumentalizado) organizacional. Nesse sentido, há uma relação entre estratégia, poder e discurso, na medida em que se reconhece que é a partir do discurso que aspectos objetivos e subjetivos associados à pluralidade de conceitos e abordagens do fazer estratégia são articulados (EZZAMEL; WILLMOTT, 2008).

A proposta de Allard-Poesi (2010) permite verificar uma série de possibilidades intervenientes ao fazer estratégia, a partir da abordagem foucaultiana. Uma vez inscritas em um campo de poder, as práticas estratégicas emergem como o resultado de múltiplas condições e de eventos aleatórios. Assim, a estratégia pode ser vista como um conjunto heterogêneo de práticas discursivas e materiais, governadas por regras que estruturam aquilo que pode ser interpretado, lido, dito ou feito sobre a realidade (ALLARD-POESI, 2010).

Partindo desses pressupostos, pode-se compreender como práticas discursivas: como estrategistas fazem uso do discurso em seu processo de fazer estratégia (narrativa, retórica, metáfora, atividades discursivas [justificação, legitimação e naturalização]); como discursos alternativos são utilizados para suportar ou desafiar a estratégia, definindo seus significados (dinâmicas de poder e resistência); como o significado desempenha papel importante no modo como as estratégias são compreendidas e se elas são implementadas (estratégia como construção discursiva) (HARDY; THOMAS, 2013).

\section{O ESTRATEGIZAR E A ABORDAGEM TEÓRICO-METO- DOLÓGICA DA ANÁLISE CRÍTICA DO DISCURSO}

Paralelamente ao movimento conhecido como "virada da prática" na teoria social (WHITTINGTON, 2006; ORLIKOWSKI, 2010), houve, nos estudos linguísticos, uma "virada do discurso" (ALVESSON; KÄRREMAN, 2000; VAARA, 2010b), caracterizada pela busca do sentido presente em diferentes produções discursivas. De acordo com essa nova perspectiva, o sentido não estaria no texto em si, mas sim em uma ampla rede de significados subjacentes aos diferentes discursos presentes no texto e no contexto em que estes se encontram inseridos. Com isso, seria possível compreender uma série de elementos negligenciados em análises linguísticas superficiais (VAARA, 2010b).

Para Philips, Sewell e Jaynes (2008), a análise do discurso surge no bojo desse movimento, oferecendo um quadro teórico e metodológico que permite examinar: a) processos por meio dos quais fenômenos organizacionais e gerenciais são reproduzidos e transformados; b) como organizações e práticas específicas são construídas discursivamente; e c) como processos linguísticos no nível micro, tais como conversações e retóricas, encontram-se no centro da atividade organizacional (VAARA, 2010b).

Apesar de a análise do discurso ser cada vez mais comum na pesquisa organizacional (CORNELSEN, 2009; CEDERSTRÖM; SPICER, 2013), essa difusão ainda não foi efetivamente observada no campo de estudos sobre estratégia em organizações (PHILIPS; SEWELL; JAYNES, 2008) e no campo de estudos sobre estratégia como prática social (VAARA, 2010a). Entretanto, Philips, Sewell e Jaynes (2008) ressaltam que uma forma específica de análise do discurso, caracterizada como análise crítica do discurso, possui potencial significativo para contribuir para a pesquisa sobre estratégia.

A análise crítica do discurso, na medida em que permite melhor compreender os aspectos discursivos da estratégia e do estrategizar a partir de um ponto de vista crítico, pode ajudar a apreender diferentes abordagens do pensamento estratégico (PHILIPS; SEWELL; JAYNES, 2008), incluindo aí a estratégia como prática social (VAARA, 2010a). A origem da análise crítica do dis- 
curso remete aos trabalhos de Fairclough (1992, 2001a, 2001b, 2003, 2005, 2010; CHOULIARAKI; FAIRCLOUGH, 2010), que permitem examinar o papel constitutivo dos discursos na sociedade (VAARA, 2010a). Para estabelecer uma relação entre o nível micro do uso cotidiano da linguagem e o nível macro da estrutura social, Fairclough tratou o uso da linguagem como uma forma de prática social - o discurso é definido e limitado pelas estruturas sociais, enquanto a prática discursiva irá definir as estruturas sociais que a limitam. Assim, é através do discurso como prática social que a estrutura social se manifesta (PHILIPS; SEWELL; JAYNES, 2008).

A análise crítica do discurso busca revelar suposições tidas como certas nas esferas sociais, societais, políticas e econômicas e examinar as relações de poder entre vários tipos de atores e discursos (VAARA, 2010a). Os discursos não são vistos como neutros em termos de conteúdo ideológico, mas sim como o lócus central da ideologia. Vaara (2010a) demonstra que não se pode entender textos e discursos sem considerar o contexto social e histórico em questão. Nesse sentido, Fairclough (2010) aponta que os discursos devem ser analisados no nível dos elementos textuais (micro), da prática discursiva (produção, consumo e interpretação de textos) e da prática social (contexto institucional e situacional).

Philips, Sewell e Jaynes (2008) apontam que existem três categorias de fenômenos sociais que são produzidas através dessa relação entre texto, discurso e contexto social: a categoria das posições do sujeito, ou seja, os locais no espaço social a partir dos quais os atores produzem os textos; a categoria das esferas da cultura, envolvendo construções sociais que emergem de conjuntos estruturados de textos e de atos discursivos que definem relações sociais, a partir de habilidades retóricas ou do acesso a canais de produção e distribuição do discurso; e a categoria do discurso como objeto, colocando os discursos como parte da ordem prática. Assim, engajar em práticas discursivas torna-se um ato eminentemente político, envolvendo disputas de poder dentro e fora da organização, determinando a natureza dos discursos, as posições dos sujeitos e o controle dos objetos resultantes desse discurso.

Vaara (2010a) demonstra ainda que pesquisadores da análise crítica do discurso reconhecem a importância da intertextualidade, visualizando os textos como parte de longas cadeias textuais. Sendo assim, o significado criado em um ato discursivo particular não pode ser entendido sem a consideração do "conhecimento comum" ou daquilo que já foi dito antes sobre o objeto do discurso. Esse aspecto é também relacionado à interdiscursividade, envolvendo como gêneros e discursos específicos são interligados e constituem "ordens de discurso" particulares, ou seja, conjuntos de relações entre discursos em um dado contexto social. Essas ordens do discurso podem ser vistas como reflexos discursivos da ordem social, ajudando a entender os aspectos discursivos das estruturas sociais (VAARA, 2010a).

A análise crítica do discurso pode fornecer avanços na compreensão do papel central de textos estratégicos formais, da construção discursiva de conceitos de estratégia e da subjetividade presente em conversações envolvendo o estrategizar organizacional, dos processos de legitimação no e através do discurso estratégico e da ideologia do discurso estratégico como um corpo de conhecimento e práxis (VAARA, 2010a). Em suma, Vaara (2010a) defende que a referida abordagem permite o mapeamento e compreensão do papel das práticas discursivas que perpassam os processos e atividades constitutivas da estratégia e do fazer estratégia na sociedade contemporânea.

\section{PROCEDIMENTOS METODOLÓGICOS}

Adotou-se a abordagem qualitativa de pesquisa (DENZIN; LINCOLN, 2000; GODOY, 2013) como ponto de partida para a compreensão das práticas estratégicas discursivas no 
contexto do setor de produção de cervejas artesanais no Brasil. O método qualitativo tem sido considerado como o mais apropriado para a averiguação de questões associadas à natureza e à dinâmica da estratégia como prática em organizações, sobretudo devido a seu caráter circular e reflexivo (HUFF; NEYER; MÖSLEIN, 2010).

Visando à constituição do corpus da pesquisa, foram coletados dados por meio de pesquisa documental, através de vídeos e textos publicados na web sobre a temática abordada neste trabalho. Pesquisas de materiais publicados na web foram realizadas entre 22/09/2013 e $28 / 11 / 2013$. Para a pesquisa, foram utilizadas ferramentas de busca disponíveis na internet. Inicialmente, buscas foram realizadas utilizando-se as seguintes palavras-chave: "cerveja", "artesanal", "Brasil". Materiais obtidos a partir dessa busca foram analisados com base na presença de discursos sobre legislação associada à indústria cervejeira e estrutura de mercado, modos de produção de cervejas artesanais e posturas de comercialização e consumo de cervejas artesanais no mercado brasileiro. Considera-se, nesse sentido, a produção e publicação de material na web como mecanismos para criação e disseminação de discursos direcionados a transformar a realidade da produção e consumo de cervejas no mercado brasileiro.

Os discursos analisados no âmbito deste trabalho foram extraídos de entrevistas em texto ou vídeo produzidas por representantes de oito cervejarias artesanais e de cinco movimentos relacionados à produção e consumo de cervejas artesanais no Brasil (Quadro 1).

Quadro 1 - Fontes de dados

\begin{tabular}{|c|c|}
\hline \multicolumn{2}{|c|}{ Agentes } \\
\hline Representante cervejaria A & Representante cervejaria $\mathrm{E}$ \\
\hline Representante cervejaria B & Representante cervejaria $\mathrm{F}$ \\
\hline Representante cervejaria C & Representante cervejaria G \\
\hline Representante cervejaria D & Representante cervejaria $\mathrm{H}$ \\
\hline \multicolumn{2}{|c|}{ Grupos } \\
\hline Movimento SlowBier Brasil & Beba Menos, Beba Melhor \\
\hline Bebendo Bem & \multirow[t]{2}{*}{ Acerva Mineira } \\
\hline Blog Confraria Conveniência & \\
\hline
\end{tabular}

Fonte: elaborado pelos autores.

$\mathrm{Na}$ segunda etapa, buscas específicas foram realizadas, considerando como palavraschave os nomes dos movimentos, cervejeiros e cervejarias apontados no Quadro 1. Tais buscas foram realizadas com o intuito de aprofundar narrativas desses agentes identificadas na primeira etapa de coleta de dados. Cumpre destacar que, por questões de confidencialidade, os representantes de cervejarias serão identificados por referências fictícias.

Posteriormente, os discursos foram analisados por meio da abordagem da análise crítica do discurso (FAIRCLOUGH, 1992, 2001a, 2001b, 2003, 2005, 2010). Para tanto, foram considerados os três níveis de análise: 1) contexto institucional da indústria de cervejas no Brasil; 2) práticas discursivas de agentes e grupos envolvidos na produção e consumo de cervejas artesanais no Brasil; e 3) ações desenvolvidas por agentes e grupos em busca da legitimação da cervejaria artesanal no Brasil. Esses três níveis remetem às recomendações desenvolvidas por Fairclough (2010) e Vaara et al. (2010b) para se analisar os discursos, considerando: o nível textual (elementos textuais), o nível das práticas discursivas (a produção e interpretação de textos) e o nível da prática social (contexto situacional e institucional da produção textual). Além disso, esse procedimento foi estruturado com vistas a cumprir com os objetivos da pesquisa, e assumindo, como base para as análises, as abordagens e concepções articuladas no quadro teórico que fundamenta o presente trabalho. 


\section{PRÁTICAS ESTRATÉGICAS DISCURSIVAS NA INDÚS- TRIA BRASILEIRA DE CERVEJAS ARTESANAIS}

Nesta seção, serão apresentados e discutidos os resultados da pesquisa. Primeiro, será apresentado o contexto da indústria cervejeira no Brasil, tal como interpretado por agentes presentes no segmento de cervejas artesanais. Em seguida, procura-se compreender o posicionamento desses agentes em criar um campo marcado por práticas discursivas, disputas de poder e ideologias. Por fim, identificam-se algumas ações e organizações de agentes inseridos na indústria de cervejas artesanais, de modo a suportar a configuração de práticas estratégicas discursivas voltadas para a legitimação desse campo organizacional no Brasil.

\subsection{O contexto da indústria de cervejas artesanais no Brasil: a construção do campo organiza- cional e a busca por institucionalização}

Estudos revelam que a cerveja se disseminou no Brasil ainda no período colonial, sob influência da Inglaterra, até então a maior produtora da bebida no mundo (SANTOS, 2003; FLACH, 2012; MOREIRA et al., 2013). Com a instalação de comerciantes ingleses no Brasil, e mediante a grande influência comercial e cultural exercida pela Inglaterra sobre Portugal, a cerveja foi difundida entre as classes mais ricas da Colônia (SANTOS, 2003).

Santos (2003) aponta que o domínio da cerveja inglesa no Brasil, especialmente as cervejas estilo porter e pale ale, persistiu até o ano de 1889. A partir do final da década de 1880 , a cerveja de origem alemã, vendida em garrafas, ganhava gradativamente a preferência do consumidor brasileiro. A preferência nacional pela cerveja vinda da Alemanha coincidiu com o crescimento da cerveja deste país em toda a Europa a partir da segunda metade do século XIX. Isto se deve ao surgimento da cerveja clara, dourada, de baixa fermentação, de aroma mais suave e de maior apelo visual servida em copos de vidro. Essas cervejas lager, nascidas na região da Bohemia e difundidas por cervejarias da Baviera, tornavam-se cada vez mais populares em relação às tradicionais cervejas turvas e de alta fermentação produzidas na Inglaterra (SANTOS, 2003).

Nesse período, a produção da bebida no Brasil começava a crescer sob influência da cerveja alemã, porém com qualidade inferior e com preços mais baixos. As primeiras cervejarias industriais surgiram no Brasil na década de 1880, a partir da abertura de empresas tais como a Companhia Cervejaria Brahma, no estado do Rio de Janeiro, e a Companhia Antarctica Paulista, no estado de São Paulo (SANTOS, 2003). Por décadas, essas duas cervejarias se posicionaram entre as líderes do mercado brasileiro, até que, no final da década de 1990 e início da década de 2000, fundiram-se para a criação da Ambev (MOREIRA et al., 2013). A criação da Ambev pode ser visualizada, no contexto da abertura da economia brasileira a partir dos anos 1990, dentro dos esforços para a criação e o fortalecimento de grandes empresas nacionais. Além disso, essa fusão se insere num movimento de grandes cervejarias internacionais, tais como a Anheuser-Bush e a Heineken, que desencadearam uma série de fusões e aquisições visando aumentar a variedade de produtos, economias de escala e acesso a novos mercados (MOREIRA et al., 2013).

Atualmente, o mercado de cervejas no Brasil é composto por quatro grandes players: a) InBev-Anheuser-Busch, criada a partir da fusão entre a brasileira Ambev, a belga InterBrew e a norte-americana Anheuser-Busch; b) Heineken, que iniciou operações no Brasil a partir da compra da Femsa, então proprietária da cervejaria Kaiser; c) Brasil Kirin, de capital japonês, que adquiriu a cervejaria brasileira Schincariol; e d) Cervejaria Petrópolis, de capital nacional e fundada por exfuncionários da Schincariol. O mercado cervejeiro no Brasil reflete a preferência, consolidada há 
tempos, pela cerveja lager, aqui denominada "tipo pilsen", suavizada e barateada pela adição de adjuntos não maltados e com foco na produção em grande escala (MOREIRA et al., 2013).

Entretanto, a partir do final da década de 1980 e especialmente na atualidade, cresce no Brasil uma nova modalidade de produção de cervejas no Brasil, considerando um enfoque artesanal e lógicas distintas daquelas legitimadas na indústria cervejeira. Inspirada na revolução das microcervejarias observada nos Estados Unidos nas décadas de 1970 e 1980, a indústria brasileira de cervejas fundamenta-se numa estratégia de produção de pequenos volumes de cerveja com alto valor agregado (KALNIN; CASAROTTO FILHO; CASTRO, 2002). O cuidado na fabricação, a atenção e retorno às tradições cervejeiras, a sofisticação dos produtos e a ligação entre a produção de cervejas e as comunidades regionais são aspectos centrais na produção artesanal (LamertZ; HEUGENS; CALMET, 2005).

O cenário criado a partir do crescimento da produção artesanal de cervejas no Brasil torna-se marcado por iniciativas voltadas à busca de legitimidade e institucionalização de novas práticas associadas ao consumo e à produção da bebida. De acordo com os dados obtidos na pesquisa, essa busca é, entretanto, marcada por enfrentamentos entre cervejarias artesanais e: a) a atual estrutura tributária para o ramo; b) a lógica de mercado criada pelas grandes empresas e c) a interpretação estabelecida sobre a forma como a cerveja é produzida e consumida.

Segundo interpretação de agentes presentes no segmento de cervejas artesanais, o mercado dominado por grandes empresas reflete-se numa estrutura tributária que impõe barreiras à viabilidade e consolidação da produção artesanal:

Quando a gente chegou já tinha um universo tributário feito pra empresa grande. E a gente não tem conseguido nada de governo algum. A gente é tratado igual grande que tem uma escala enorme. (Representante Cervejaria A).

Cinco anos atrás praticamente não havia esse mercado de cervejas artesanais. Então todas as legislações são feitas para grandes cervejarias. E as micro não se enquadram. Hoje é praticamente inviável se ter uma microcervejaria. Os impostos são calculados de acordo com o preço da cerveja na gôndola. Então, se sua cerveja custa mais caro, você vai pagar um imposto mais alto. Mas a nossa cerveja é mais cara não porque queremos lucros maiores. Ela é mais cara porque o volume de compra nosso é menor. O preço da nossa matéria-prima é mais alto. (Representante Cervejaria B).

As narrativas expostas revelam a construção de práticas discursivas voltadas, inicialmente, para uma interpretação questionadora da estrutura tributária brasileira, tida como inadequada para esse setor emergente. Os agentes questionam ainda as regulamentações do produto por parte do Ministério da Agricultura, principal órgão regulador do ambiente institucional. As normas estabelecidas pelo Estado são apontadas como obsoletas e alinhadas ao padrão de cerveja consolidado no Brasil, reforçando a hegemonia da grande indústria:

[As microcervejarias têm a capacidade de] lançar novos produtos de forma rápida, o que não seria viável para uma grande cervejaria. Mas o Ministério da Agricultura vem demorando muito pra liberar rótulos de cervejas diferentes. Quando é uma cerveja que até então era desconhecida internamente, eles não têm o conhecimento necessário para liberar. Temos rótulos que estão há dois anos aguardando liberação e provavelmente não serão liberados. (Representante Cervejaria B).

Aliado à estrutura reguladora, identifica-se um discurso que aponta para a necessidade de se estabelecer uma cultura receptiva ao modo de produção e consumo de cervejas artesanais: 
Nossa lei não dá abertura porque volta para o problema da cultura. A gente não tem uma cultura de cerveja. Então a nossa lei é extremamente defasada perto de outros países. A cerveja chegou aqui há 200 anos, mas cresceu há pouco menos de 100. Até pouco tempo cerveja era bebida de classe alta. Classes C e D não bebiam cerveja, bebiam cachaça, vinho. Então nós não temos abertura para variedades de estilos na legislação, o mercado brasileiro não tinha isso até pouco tempo. (Representante Cervejaria H).

Verifica-se, portanto, a construção de uma interpretação dominante para a indústria cervejeira no Brasil, caracterizada por uma estrutura reguladora e tributária criada para a lógica da produção em massa, para a grande empresa e para a padronização da cerveja como produto. Essa interpretação reflete uma cultura em que a cerveja artesanal não encontra terreno fértil para disseminação. Diante desse cenário, desenvolvem-se narrativas para suportar movimentos de oposição, a fim de, simultaneamente, legitimar a produção e consumo de cervejas artesanais e combater a lógica estabelecida pelo atual cenário da indústria cervejeira.

\subsection{As práticas discursivas da indústria de cervejas artesanais no Brasil: formação de um campo de disputas de poder e ideologias}

A análise do material documental levantado a partir da pesquisa permitiu identificar tentativas de criação de discursos que marcam oposições em relação à interpretação dominante para a indústria cervejeira no Brasil. Tem-se, nesse sentido, a busca pela construção de discursos de oposição em relação ao ato de consumir e de produzir cervejas, bem como sobre formas de relacionamento entre cervejarias e mercado.

No que tange ao consumo de cervejas, a configuração do campo de disputas de poder e ideologias é moldado a partir de uma ordem discursiva que combate a naturalização e banalização do ato de consumir cervejas:

$O$ ato de beber é trazer consciência. A gente está educado a beber sem pensar; descer redondo, tomar e não pensar. Mas não é melhor tomar pensando? É tão melhor tomar em câmera lenta, tomar 10 cervejas diferentes numa noite. Não que beber cerveja sem pensar é errado, mas não é a única maneira [...]. A gente está muito dominado pelas grandes corporações e estamos esquecendo o que são as coisas regionais. Tá todo mundo de saco cheio de ser levado pela mão, de ser levado pela propaganda. O cara quer tomar a decisão dele. Então essas cervejas que não são invasivas, de querer lavar a mente do cara, naturalmente vão conquistando o paladar. O cara começa a tomar cerveja especial, ele não volta a tomar Skol. (Representante Cervejaria A).

As cervejas de massa são rotuladas como sendo um produto para consumo "sem pensar". No trecho exposto, o Representante da Cervejaria A retoma o slogan de uma grande companhia do setor no Brasil: ao "descer redondo", a cerveja comercializada pelas grandes indústrias promove uma "lavagem cerebral", ressignificando o comportamento do consumidor ao levá-lo a um ato de consumo despropositado e, em certa medida, banalizado. Por outro lado, verifica-se a formação de uma prática discursiva que busca posicionar o consumo de cervejas artesanais de outra maneira, estruturada através de um ato consciente e engajado. Esse percurso é ilustrado pela possibilidade de se beber "pensando", em "câmera lenta". Nesse cenário, o consumidor teria autonomia para "tomar a decisão dele", livre de influências das grandes corporações e da propaganda. De modo complementar, esse posicionamento alternativo também se manifesta através da emergência de práticas discursivas que buscam fomentar um consumo responsável, que valoriza a qualidade em detrimento da quantidade: 
Nos dias de hoje, estamos vivenciando uma nova maneira de encarar o consumo de cervejas. Se antes a bebida era simplesmente vinculada com o ato de simplesmente se embriagar ou se refrescar nos dias quentes [...]. A cerveja está sendo vista como uma grande acompanhante para a gastronomia e o seu consumo consciente é incentivado pelas empresas do setor que têm um viés mais responsável. Não bebemos mais cerveja somente para encher a cara, mas para experimentar aromas e sabores diferenciados, dignos de uma cultura milenar. (Blog Bebendo Bem).

Na hora de comprar aqueles fardos de Crystal, opte por duas ou três garrafas de uma cerveja de qualidade, fuja das cervejas Ambev [...]. Compreendo que a rotina de beber várias é difícil de largar, mas acredite, uma garrafa de $500 \mathrm{~mL}$ de cerveja Dunkel vale por várias águas 'Glacial-Skol'. Temos o fator valor que afeta na hora, aquela dúvida de comprar uma ou 12 latinhas, mas ainda assim, vale muito a pena pagar um pouco mais por uma garrafa onde os ingredientes são bem selecionados, a produção é cuidadosa e os rótulos são bem pensados. É a preferência pela qualidade em vez da quantidade. (Blog Confraria Conveniência).

Diante disso, ao valorizar uma "nova maneira de encarar o consumo de cervejas", em que se deixa de beber para "se embriagar ou para se refrescar em dias quentes" e passa-se a considerar a cerveja como um produto gastronômico e voltado para um consumo mais responsável, os agentes posicionam a bebida artesanal em um prisma ideológico diferenciado e questionador. Sob o ponto de vista da produção, esse prisma é ainda reforçado por práticas discursivas que combatem a excessiva padronização das cervejas de massa e fomentam o resgate de culturas cervejeiras e a incorporação da personalidade do mestre cervejeiro no produto:

Temos que produzir nossas cervejas, temos que redescobrir estilos perdidos no tempo. Você chega no mercado tem 10 marcas de dois ou três estilos muitíssimo semelhantes. Então, para nós quebrarmos essa limitação imposta pelo mercado, temos que produzir nossas próprias cervejas e estimular que cervejarias pequenas também produzam [...]. Fazer cerveja tem toda uma história de estilo, de gosto do cervejeiro, tem todo um carinho, ela está impregnada de personalidade. Quando eu tiro essa personalidade e boto uma coisa sem alma e que seja bem fácil de ser vendida (com drinkability muito grande) eu não estou mais fazendo, é a máquina que está fazendo. Isso não é artesanal. Tudo o que for pensado com bons ingredientes, com boas práticas, aí não interessa se é com máquina ou sem máquina (máquina é importante), com personalidade é o que interessa. (Representante Cervejaria H).

Dentro desse novo conjunto de práticas de produção, pode-se destacar, de um lado, a produção de discursos que enfatizam a necessidade de rompimento com a "limitação imposta pelo mercado" e com a "massificação de estilo", para que seja possível produzir cervejas que possibilitem "redescobrir estilos perdidos no tempo", as quais incorporam ideologias associadas à produção artesanal. Nesse sentido, práticas discursivas que apontam para assertivas que visam orientar a ação dos produtores artesanais ("faça a cerveja que você gosta", "defina uma identidade para a sua cerveja"), legitimadas e reproduzidas por diferentes mestres cervejeiros, sintetizam essa inclinação de microcervejarias ao resgate de estilos e de tradições ao redor da bebida, recuperando o caráter ideológico da produção ao ressignificar aquilo que os agentes denominam como "cultura cervejeira", configurada como uma prática de resistência.

Por fim, as relações entre cervejaria e mercado também demarcam aspectos de disputa de poder e entre diferentes ideologias. Do ponto de vista da indústria de cervejas artesanais, verifica-se que, a partir do movimento de incorporação da personalidade do cervejeiro à bebida, surge uma nova estratégia de comercialização do produto, baseada na busca por certa autonomia da cervejaria em relação à demanda e às regras do mercado: 
[Somos] uma cervejaria familiar. Então, eu, meu pai e meu irmão produzimos de acordo com o que a gente quer. Não fazemos pesquisa de mercado, a opinião do cervejeiro é o que vale. Nós decidimos e fazemos acontecer (Representante da Cervejaria C).

Nunca desvirtuar sua cerveja porque o mercado está pedindo mais, ou porque o preço está cada vez melhor. A cerveja é um pouco de você que você está servindo ao consumidor. É a sua arte em estado líquido. (Representante Cervejaria G).

O discurso propagado pela microcervejaria revela, em certa medida, a busca de uma alternativa de comercialização, em que o cervejeiro se coloca como um agente dotado de certa autonomia, sendo "sua opinião a que vale" no atendimento ao mercado. Esse movimento também imprime uma prática de resistência, na medida em que se busca "nunca desvirtuar [a] cerveja porque o mercado está pedindo mais, ou porque o preço está cada vez melhor", posicionando-se de maneira ideológica, para fornecer não um simples produto, mas sim "arte em estado líquido". Além disso, a diferenciação nos atos de comercialização de cerveja também pode ser observada a partir das estratégias de marketing:

Desde 2005, quando começamos, a gente vem crescendo em média $30 \%$ ao ano. É um crescimento controlado. A gente conseguiria crescer mais, mas não de forma saudável, sem alterar a qualidade do produto. A gente não entra no que é o mercado cervejeiro. A gente não patrocina ponto de venda, pintando a fachada. Queremos que o estabelecimento compre nossa cerveja porque acredita ser um produto bom, que vai render mais clientes a ele. (Representante Cervejaria B).

A ênfase ao "crescimento controlado", planejado para não "alterar a qualidade do produto", dada no discurso, busca levar a um direcionamento para a qualidade, além de tirar do foco estratégias de expansão consolidadas na indústria cervejeira e centradas em produção em escala e em aquisições. Além disso, pode-se observar uma oposição às práticas de comercialização geralmente adotadas pela grande indústria. Como estratégia de marketing, adotam um conjunto de práticas discursivas para construir a imagem de uma cerveja que se encontra impregnada de tradição, qualidade, personalidade e originalidade:

Não é pra brigar, falar que minha cerveja é melhor que a sua, mas pra ensinar a beber; o estilo de cerveja é assim. Nesse estilo se esperam essas características, naquele estilo se esperam outras. A partir do momento em que você ensina, você não ensina a beber o meu ou o seu, mas a beber produtos de qualidade. (Representante Cervejaria H).

A gente fala a verdade ao invés de fazer propaganda. Qualquer um vai lá na Colorado e vê como é que se faz. Eu já chamei vários colegas, todo mundo viu a receita, o processo de fabricação, não tem caixa preta. Qualquer um que vai fazer com um toque diferente do meu. Tem lugar para todo mundo, e o importante é a gente apoiar o pequeno negócio, senão o mundo vai esquecer isso. (Representante Cervejaria A).

Há, portanto, um padrão nos discursos dos cervejeiros artesanais, que procura vincular o ato de comercialização desses produtos a uma prática de educação para o consumo consciente e engajado, uma vez que se "ensina [...] a beber produtos de qualidade". Essa estratégia de educação para o consumo consciente de cervejas artesanais revela, adicionalmente, o embate entre a pequena cervejaria e a grande indústria, na medida em que, segundo cervejeiros artesanais, a primeira "fala a verdade ao invés de fazer propaganda". Por fim, práticas discursivas de cervejeiros artesanais buscam justificação de preços mais elevados, fundamentando-se numa lógica que rejeita a competição no sentido tradicional e fomenta a qualidade do produto: 
A competição estraga tudo. Ela vai prejudicando todo mundo. Competição geralmente envolve preço, quando a gente está falando de grande indústria. O que acontece? Ganha quem tem o menor preço e o menor preço vai prensando todo mundo lá em baixo. $O$ cervejeiro ganha menos, o cara que planta cevada tem que ter uma cevada de pior qualidade, o cara que transporta a cevada quer fazer isso da forma mais rápida possível. Só quem perde nisso é o consumidor. E o consumidor quer ser surpreendido pela cerveja. (Representante Cervejaria A).

Hoje uma cerveja da Colorado custa, em média, $\mathrm{R} \$ 10,00$ com seus $600 \mathrm{~mL}$, já uma Skol litrão custa cerca de $\mathrm{R} \$ 4,00$. Com uma diferença monetária tão grande fica complicado para o consumidor largar sua cerveja litrão e encarar uma coisa nova que ele não sabe se vai gostar e ainda é mais que o dobro da que ele bebe. Então aí que entra o título do post 'Beber menos e Beber melhor vale a pena?' e com uma única palavra eu respondo: SIM. O segredo dessa mudança é a qualidade da cerveja. Não podemos comparar uma cerveja que é feita em grande quantidade, utilizando ingredientes baratos, com uma microcervejaria que utiliza do melhor para produzir cervejas fantásticas. Tomar cerveja artesanal é um caminho sem volta, então corra que vale a pena! (Movimento Beba Menos, Beba Melhor).

Os preços mais altos de cervejas artesanais são fundamentados, em primeiro lugar, pelo discurso da qualidade e da saúde da cadeia produtiva da cerveja. Ainda nesse discurso da qualidade como instrumento para justificativa de preços mais elevados, verifica-se o estabelecimento de contrapontos entre cervejas de massa e artesanais, fundamentados a partir de uma diferenciação que marca os atos de produção, comercialização e consumo de cerveja.

Portanto, diante do campo de conflitos estabelecidos entre a indústria cervejeira estabelecida e cervejarias artesanais, pode-se identificar um conjunto de ações e organizações que, tomadas por parte destes últimos, buscam legitimar as lógicas institucionais fomentadas pela produção artesanal de cervejas, as quais serão exploradas no próximo tópico.

\subsection{As cervejas artesanais e as práticas dos agentes na busca pela legitimação}

Os dados obtidos na pesquisa relevaram movimentos e organizações que buscam atuar na reprodução de discursos destinados à consolidação do campo de cervejarias artesanais no Brasil: a criação de instituições voltadas para a defesa dos interesses dos cervejeiros artesanais (Associações de Cervejeiros Artesanais - ACervAs); a criação do movimento conhecido como SlowBier Brasil; e a criação do movimento "Beba menos, beba melhor".

As ACervAS são associações sem fins lucrativos e têm por finalidade a reunião de produtores artesanais de cerveja, buscando fomentar a cultura cervejeira, ensinar e transmitir aos consumidores os valores inerentes ao consumo de cerveja artesanal e articular os interesses dos agentes inseridos nesse campo organizacional.

O movimento SlowBier Brasil é inspirado no movimento SlowBier nascido na Europa e na revolução das microcervejarias (The MicroBrewery Revolution) ocorrida nos Estados Unidos. A filosofia desse movimento defende, segundo o site do SlowBier Brasil, o "resgate da história, da cultura e do prazer de se fazer e de se beber boas bebidas, associadas naturalmente à gastronomia de qualidade". Trata-se, portanto, da incorporação de discursos externos, vindos especialmente da Alemanha, Inglaterra e Estados Unidos, de modo a buscar legitimidade interna para a produção e consumo de cervejarias artesanais. Essa incorporação, entretanto, ocorre em conjunção com símbolos que buscam conferir traços brasileiros ao discurso externo para legitimá -lo frente aos consumidores. Nesse sentido, os articuladores do movimento no Brasil utilizam a imagem do bicho-preguiça em vez do caramujo, símbolo do movimento internacional. 
A terceira e última prática estruturada para a construção da legitimação da cerveja artesanal no Brasil envolve uma iniciativa da Cervejaria Abadessa, do Rio Grande do Sul, intitulada como movimento "Beba menos, beba melhor". Essa prática, inspirada em uma campanha da Associação Alemã de Cervejeiros (Di Deutschen Brauer), procura agregar consciência ao ato de consumo da cerveja. Atualmente, diferentes cervejarias artesanais brasileiras, tais como Wals, Bamberg e Falke Bier, adotam o selo do movimento em seus produtos. A exemplo do Slow Bier, esse movimento busca a incorporação de discursos externos, emulando práticas vindas do exterior para buscar legitimidade e identidade para o mercado brasileiro de cervejas artesanais.

A partir dos discursos propagados por essas três iniciativas, é possível identificar alguns pilares que as microcervejarias buscam para sustentar sua legitimidade no Brasil. O primeiro pilar se refere à busca por colaboração com agentes institucionais, de modo a construir um ambiente regulatório mais receptivo à produção artesanal:

Faz-se necessário neste momento reafirmar o grande passo dado pelos cervejeiros associados em Minas Gerais, que foi o de aproximar-se do MAPA (Ministério da Agricultura, Pecuária e Abastecimento), um órgão regulador que muitas vezes acaba sendo visto como inimigo ou dificultador, no qual procuramos o apoio de seus técnicos para que o produto artesanal, dentre eles o caseiro, não seja mais encarado como ilegal [...]. Como consequência de nosso passo, os técnicos do MAPA em Minas Gerais buscaram apoio da Acerva Mineira para aprender mais sobre os diferentes estilos da bebida, além de aspectos produtivos, microbiológicos, tecnológicos, de forma que, munidos de informação correta, possam ter subsídios para opinar nacionalmente na modificação, ampliação e melhoria das normas reguladoras do segmento (Acerva Mineira).

O segundo pilar encontra-se relacionado à educação para o consumo de cerveja, que busca reforçar um discurso de qualidade e disseminar entre os consumidores novas concepções relacionadas ao ato de se produzir e beber cerveja. Nesse contexto, o discurso do SlowBier Brasil se mostra relevante, apontando, além da qualidade, um discurso de inclinação ambiental para legitimar as cervejas artesanais:

As microcervejarias fabricam preferindo em seu processo de produção práticas social e ambientalmente responsáveis, além do que produzem sem adição de conservantes artificias, com base na Lei de Pureza Alemã de 1516 que admite apenas malte, lúpulo e água na composição da cerveja, gerando um alimento com maior integridade. Também não é segredo que o processo de fabricação artesanal gera muito menos impactos no meio ambiente que o processo industrial. (SlowBier Brasil).

Ainda em relação à educação, mas com um viés para o consumo responsável, o movimento "Beba menos, beba melhor" busca disseminar o discurso de "menos bebedeira, mais prazer" no ato de consumir cervejas, tal como já ressaltado nesta seção.

O terceiro pilar se refere à sustentabilidade do negócio, mediante colaboração e criação de eventos que sejam capazes de sustentar, do ponto de vista econômico e mercadológico, a produção de cervejas artesanais:

É um negócio como qualquer outro; a diferença é que ele [o cervejeiro] é apaixonado [...]. Eu não quero ter clientes exclusivos, porque eu não tomo só Colorado, eu tomo as cervejas dos meus amigos também. Eu acho que o legal nesse nosso mundo da cerveja pequena é a camaradagem em volta da cerveja. (Representante Cervejaria A).

A gente acredita que a única forma de crescer é crescer junto, a gente tem que trocar informações, se falta matéria-prima a gente empresta. (Representante Cervejaria D). 
Temos que nos juntar porque o nosso mercado é tão pequeno que um tem que vender o outro, porque no mercado de artesanais a pessoa quer experimentar, degustar, conhecer novos sabores. (Representante Cervejaria E).

Observaram-se, portanto, diferentes ações e práticas discursivas que dão sustentação ao processo de construção da legitimidade da produção e consumo de cervejas artesanais no Brasil.

A Figura 1 apresenta uma síntese dos resultados, considerando: (1) a interpretação dos agentes sobre o contexto; (2) os discursos emergentes do segmento de cervejas artesanais para consumo, produção e mercado, bem como os conflitos com a lógica dominante para cervejas no Brasil; e (3) os movimentos e organizações destinados à propagação de discursos gerados no segmento de cervejas artesanais.

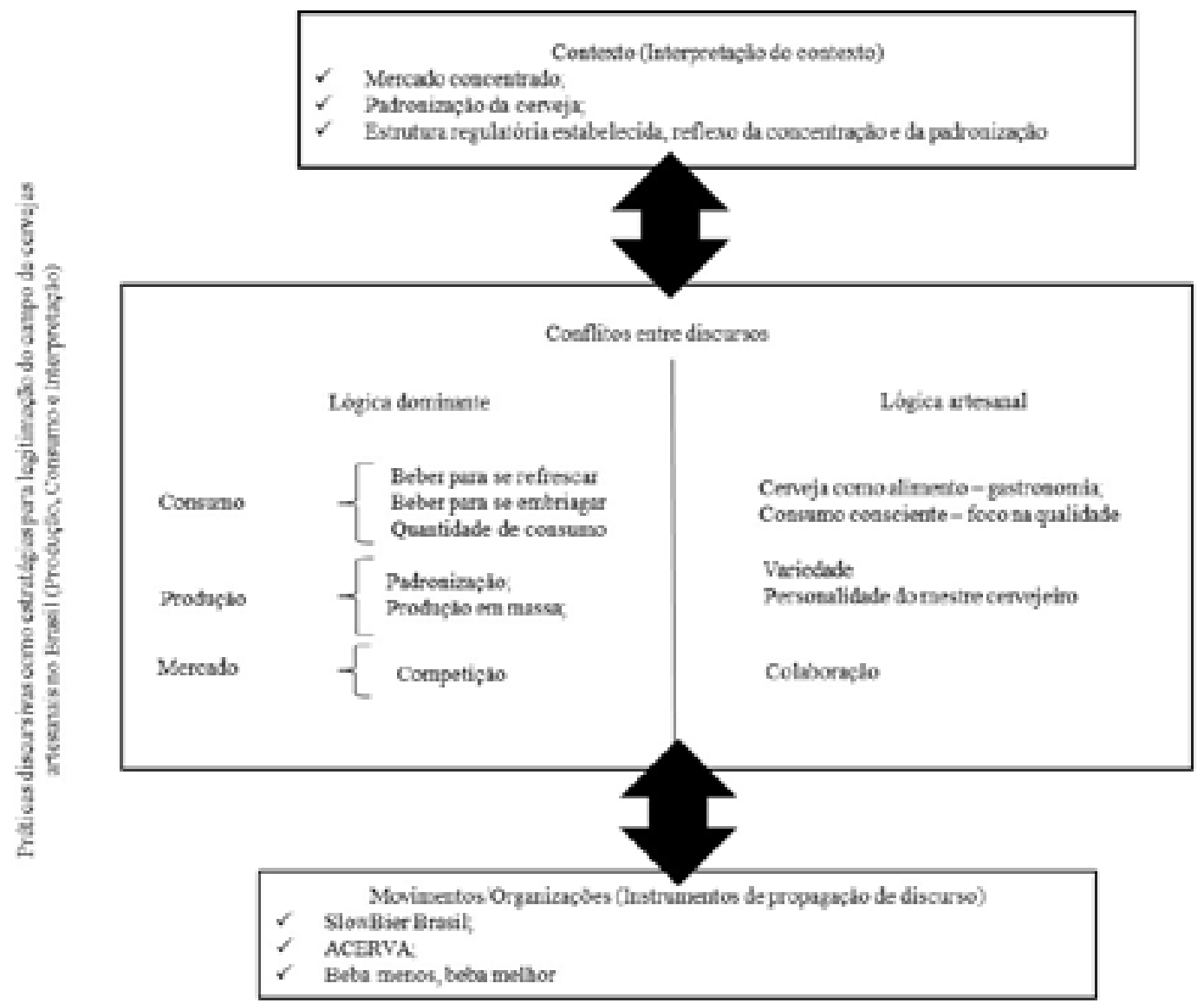

Figura 1 - Síntese de resultados: contexto, discursos e movimentos relacionados à busca por institucionalização do segmento de cervejas artesanais

Fonte: elaborada pelos autores.

Como visto ao longo da presente seção de análise e discussão dos resultados, e com base no que está sintetizado pela figura, as práticas, desempenhadas pelos agentes inseridos nesse campo organizacional, visam conformar a atuação desses agentes junto ao ambiente institucional, conferindo possibilidades de institucionalização de suas atividades e de posicionamento de suas pequenas cervejarias como um espaço alternativo para a produção e consumo de cervejas no Brasil. 


\section{CONSIDERAÇÕES FINAIS}

O objetivo deste trabalho consistiu em identificar e compreender as práticas estratégicas discursivas voltadas para a legitimação e institucionalização da indústria brasileira de cervejas artesanais. Para tanto, procurou-se fundamentar, teoricamente, a relação entre estratégia como prática discursiva e institucionalismo e, metodologicamente, a abordagem da análise crítica do discurso, para que fosse possível apreender as práticas discursivas dos diferentes agentes e instituições inseridas nesse campo organizacional.

Os discursos dos agentes da indústria de cervejas artesanais revelaram diferentes perspectivas sobre as iniciativas em prol da institucionalização e legitimação da produção, consumo e comercialização da bebida no Brasil. Ao se constituir como um processo longo e conflituoso, marcado por disputas de poder e entre diferentes ideologias, os agentes construíram práticas discursivas que permitiram um enfrentamento das ações difundidas e institucionalizadas pelas cervejarias de grande porte, denotando resistências que contribuíram para o seu posicionamento frente ao ambiente institucional. A partir disso, os agentes empreenderam ações que visavam legitimar a produção, o consumo e a comercialização de cervejas artesanais, ressignificando discursos e práticas já consolidados no contexto brasileiro.

Os resultados apresentam evidências de que a indústria brasileira de cervejas artesanais encontra-se em um processo de institucionalização junto ao ambiente e de legitimação junto aos consumidores, através de práticas discursivas que revelam disputas de poder com as grandes cervejarias. Nesse sentido, a própria produção de cervejas artesanais é orientada por uma ideologia, caracterizada a partir de um forte posicionamento de oposição, enfrentamento e resistência a práticas já institucionalizadas no mercado cervejeiro brasileiro. Sendo assim, revelam-se possibilidades de construção de um campo próprio, estruturado por meio de estratégias discursivas que podem, no limite, levar a uma emancipação em relação ao ambiente das grandes indústrias do setor.

Este trabalho gera importantes implicações para a teoria e pesquisa sobre estratégia como prática, uma vez que este lança luzes sobre perspectivas pouco exploradas no campo do estrategizar. De um lado, ao integrar os níveis das práticas de institucionalização (macro), das práticas discursivas de disputas de poder e ideologia (meso) e das práticas dos agentes voltadas para a legitimação da produção artesanal (micro), este estudo opera em uma posição que supera algumas críticas apontadas à teoria sobre estratégia como prática. De outro lado, ao analisar o caso de uma indústria pouco explorada na literatura, abre-se possibilidade para a compreensão de outros objetos até então pouco abordados pela academia, tal como o setor de cervejas artesanais no Brasil, revelando o potencial da estratégia como prática para a realização de pesquisas na área dos Estudos Organizacionais.

\section{REFERÊNCIAS}

ALLARD-POESI, F. A Foucauldian perspective on strategic practice: strategy as the art of (un) folding. In: GOLSORKHI, D. et al. Cambridge handbook of strategy as practice. Cambridge: Cambridge University Press, 2010. p. 168-182.

ALMEIDA, M. L.; SALES, R. S. F. A estratégia como prática social e a teoria da estruturação: distâncias e aproximações. In: ENCONTRO DE GESTÃO DE PESSOAS E RELAÇÕES DE TRABALHO, 3., 2011, João Pessoa. Anais... João Pessoa: Anpad, 2011. 
ALVESSON, M.; KÄRREMAN, D. Taking the linguistic turn in organizational research: challenges, responses, consequences. Journal of Applied Behavioral Science, v. 36, n. 2, p. 136-158, jun. 2000.

BARLEY, S. R.; TOLBERT, P. S. Institutionalization and structuration: studying the links between action and institution. Organization Studies, v. 18, n. 1, p. 93-118, 1997.

BERGER, P. L.; LUCKMANN, T. A construção social da realidade: tratado da sociologia do conhecimento. 25. ed. Petrópolis: Vozes, 2005.

BOURDIEU, P. The logic of practice. Cambridge: Polity Press, 1990.

BOURDIEU, P.; WACQUANT, L. An invitation to reflexive sociology. Cambridge: Polity Press, 1992.

CANHADA, D. I. D.; RESE, N. Contribuições da "estratégia como prática" ao pensamento em estratégia. Revista Brasileira de Estratégia, v. 2, n. 3, p. 273-289, set./dez. 2009.

CEDERSTRÖM, C.; SPICER, A. Discourse of the real kind: a post-foundational approach to organizational discourse analysis. Organization, in press, 2013.

CHIA, R. Strategy-as-practice: reflections on the research agenda. European Management Review, v. 1, n. 1, p. 29-34, mar. 2004.

CHIA, R.; MACKAY, B. Post-processual challenges for the emerging strategy-as-practice perspective: discovering strategy in the logic of practice. Human Relations, v. 60, n. 1, p. 217-242, 2007.

CHOULIARAKI, L.; FAIRCLOUGH, N. Critical discourse analysis in organizational studies: towards an integrationist methodology. Journal of Management Studies, v. 47, n. 6, p. 1.213-1.218, set. 2010.

CORAIOLA, D. M.; MELLO, C. M.; JACOMETTI, M. Estruturação da estratégia-como-prática organizacional: possibilidades analíticas a partir do institucionalismo organizacional. Revista de Administração Mackenzie, v. 13, n. 5, p. 204-231, 2012.

CORNELSEN, E. L. Análise do discurso no âmbito dos estudos organizacionais: uma abordagem teórica. In: CARRIERI, A. P. et al. Análise do discurso em estudos organizacionais. Curitiba: Juruá, 2009. p. 21-44.

DENZIN, N. K.; LINCOLN, Y. S. Handbook of qualitative research. 2. ed. Thousand Oaks: Sage Publications, 2000.

EZZAMEL, M.; WILLMOTT, H. Strategy as discourse in a global retailer: a supplement to rationalist and interpretive accounts. Organization Studies, v. 29, n. 2, p. 191-217, 2008.

FAIRCLOUGH, N. Analyzing discourse: textual analysis for social research. 2. ed. London: Routledge, 2003.

FAIRCLOUGH, N. Critical discourse analysis: the critical study of language. Harlow: Longman, 2010.

FAIRCLOUGH, N. Discourse and text: linguistic and intertextual analysis within discourse analysis.

Discourse \& Society, v. 3, n. 2, p. 193-217, abr. 1992. 
FAIRCLOUGH, N. Discurso e mudança social. Brasília: Editora da UnB, 2001a.

FAIRCLOUGH, N. Language and Power. Harlow: Longman, $2001 \mathrm{~b}$.

FAIRCLOUGH, N. Peripheral vision: discursive analysis in organization studies: the case for critical realism. Organization Studies, v. 26, n. 6, p. 915-939, 2005.

FELDMAN, M. S.; ORLIKOWSKI, W. J. Theorizing practice and practicing theory. Organization Science, v. 22, n. 5, p. 1.240-1.253, set./out. 2011.

FERREIRA, R. H. et al. Inovação na fabricação de cervejas especiais na região de Belo Horizonte. Perspectivas em Ciência da Informação, v. 16, n. 4, p. 171-191, out./dez. 2011.

FLACH, L. A rota das cervejarias artesanais de Santa Catarina: analisando improvisação e aprendizagem. GESTÃO.Org: Revista Eletrônica de Gestão Organizacional, v. 10, n. 3, p. 567-594, out./dez. 2012.

FOUCAULT, M. A ordem do discurso. São Paulo: Loyola, 2010.

GIDDENS, A. The construction of society: outline of the Theory of Structuration. Berkeley: University of California Press, 1984.

GODOY, A. S. Fundamentos da pesquisa qualitativa. In: TAKAHASHI, A. R. W. (Org.). Pesquisa qualitativa em Administração: fundamentos, métodos e uso no Brasil. São Paulo: Atlas, 2013. p. 35-50.

GOLSORKHI, D. et al. Introduction: what is strategy as practice? In: GOLSORKHI, D. et al. Cambridge handbook of strategy as practice. Cambridge: Cambridge University Press, 2010. p. 1-22.

GOMEZ, M.-L. A Bourdieusian perspective on strategizing. In: GOLSORKHI, D. et al. Cambridge handbook of strategy as practice. Cambridge: Cambridge University Press, 2010. p. 141-154.

HARDY, C.; THOMAS, R. Strategy, discourse and practice: the intensification of power. Journal of Management Studies, Early View, 2013.

HUFF, A.S.; NEYER, A.-K.; MÖSLEIN, K. Broader methods to support new insights into strategizing. In: GOLSORKHI, D. et al. Cambridge handbook of strategy as practice. Cambridge: Cambridge University Press, 2010. p. 201-216.

JARZABKOWSKI, P. Strategy as practice: recursiveness, adaptation and practices-in-use. Organization Studies, v. 25, n. 4, p. 529-560, 2004.

JARZABKOWSKI, P.; BALOGUN, J.; SEIDL, D. Strategizing: the challenges of a practice perspective. Human Relations, v. 60, n. 1, p. 5-27, 2007.

JARZABKOWSKI, P.; MATTHIESEN, J. K.; VAN DE VEN, A. Doing which work? A practice approach to institutional pluralism. In: LAWRENCE, T.; LECA, B.; SUDDABY, R. (Ed.). Institutional work: actors and agency in institutional studies of organizations. Cambridge, UK: Cambridge University Press, 2009. p. 284-316.

JARZABKOWSKI, P.; SEIDL, D. The role of meetings in the social practice of strategy. Organization Studies, v. 29, n. 11, p. 1.391-1.426, 2008. 
JARZABKOWSKI, P.; SPEE, A. P. Strategy-as-Practice: a review and future directions for the field. International Journal of Management Reviews, v. 11, n. 1, p. 69-95, mar. 2009.

JOHNSON, G.; SMITH, S.; CODLING, B. Institutional change and strategic agency: an empirical analysis of managers' experimentation with routines in strategic decision-making. In: GOLSORKHI, D. et al. Cambridge handbook of strategy as practice. Cambridge: Cambridge University Press, 2010. p. 273-290.

KALNIN, J. L.; CASAROTTO FILHO, N.; CASTRO, J. E. E. Análise estratégica para implantação de empresas de pequeno porte: cervejarias artesanais. Revista Produção Online, v. 2, n. 1, p. 1-11, jun. 2002.

LAMERTZ, K.; HEUGENS, P. P. M. A. R.; CALMET, L. The configuration of organizational images among firms in the Canadian beer brewing industry. Journal of Management Studies, v. 42, n. 4, p. 817-843, jun. 2005.

LECLERCQ-VANDELANNOITTE, A. Organizations as discursive constructions: a Foucauldian approach. Organizations Studies, v. 32, n. 9, p. 1.247-1.271, 2011.

LOK, J.; DE ROND, M. On the plasticity of institutions: containing and restoring practice breakdowns at the Cambridge University Boat Club. Academy of Management Journal, v. 56, n. 1, p. 185-207, 2012.

MACHADO-DA-SILVA, C. L.; VIZEU, F. Análise institucional de práticas formais de estratégia. Revista de Administração de Empresas, v. 47, n. 4, p. 89-100, out./dez. 2007.

MACIEL, C. O.; AUGUSTO, P. O. M. A 'practice turn' e o movimento social da estratégia como prática: está completa essa virada? Revista de Administração Mackenzie, v. 14, n. 2, p. 155-178, mar./abr. 2013.

MOREIRA, E. T. et al. Concentração industrial e competitividade: uma análise do setor de cervejas do Brasil - 1997-2012. In: ENCONTRO DE ESTUDOS EM ESTRATÉGIA, 6., 2013, Bento Gonçalves. Anais... Rio de Janeiro: ANPAD, 2013.

NORD, W. Understanding Bourdieu's contribution to organization and management studies. Academy of Management Review, v. 30, n. 4, p. 855-877, 2005.

ORLIKOWSKI, W. J. Practice in research: phenomenon, perspective and philosophy. In: GOLSORKHI, D. et al. Cambridge handbook of strategy as practice. Cambridge: Cambridge University Press, 2010. p. 23-33.

PHILIPS, N.; SEWELL, G.; JAYNES, S. Applying critical discourse analysis in strategic management research. Organizational Research Methods, v. 11, n. 4, p. 770-789, out. 2008.

RASCHE, A.; CHIA, R. Researching strategy practices: a genealogical social theory perspective. Organization Studies, v. 30, n. 7, p. 713-734, 2009.

ROULEAU, L. Studying strategizing through narratives of practice. In: GOLSORKHI, D. et al. Cambridge handbook of strategy as practice. Cambridge: Cambridge University Press, 2010. p. 258-272.

SANTOS, F. S. Pesquisa de percepção de consumidores sobre cervejas premium: aplicação nas 
cervejas Eisenbahn e em algumas de suas concorrentes. 2007. 121 p. Monografia (Trabalho de Conclusão de Curso em Administração)-Universidade Federal do Rio Grande do Sul, Porto Alegre, 2007.

SANTOS, S. D. P. Os primórdios da cerveja no Brasil. Cotia: Ateliê Editorial, 2003.

SMETS, M.; MORRIS, T.; GREENWOOD, R. From practice to field: a multi-level model of practicedriven institutional change. Academy of Management Journal, v. 55, n. 4, p. 877-904, ago. 2012.

VAARA, E. Critical discourse analysis as methodology in Strategy as Practice research. In: GOLSORKHI, D. et al. Cambridge handbook of strategy as practice. Cambridge: Cambridge University Press, 2010a. p. 217-229.

VAARA, E. Taking the linguistic turn seriously: strategy as a multifaceted interdiscursive phenomenon. Advances in Strategic Management, v. 27, n. 1, p. 29-50, $2010 \mathrm{~b}$.

VAARA, E.; WHITTINGTON, R. Strategy-as-practice: taking social practices seriously. Academy of Management Annals, v. 6, n. 1, p. 285-336, 2012.

VALADÃO, J. A. D.; SILVA, S. S. D. S. Justaposições da Estratégia como Prática e Processo de Estratégia: Antes da Visão Pós-Processual da Estratégia. Revista de Administração Mackenzie, v. 13, n. 2, p. 171-195, mar./abr. 2012.

WALTER, S. A.; BACH,. T. M.; BARBOSA, F. Estratégia como prática: análise longitudinal por meio de bibliometria e sociometria. Revista Brasileira de Estratégia, v. 5, n. 3, p. 307-323, set./dez. 2012.

WHITTINGTON, R. Completing the practice turn in strategy research. Organization Studies, v. 27, n. 5, p. 613-634, out. 2006.

WHITTINGTON, R. Practice perspectives on strategy: unifying and developing a field. Best Paper Proceedings, Academy of Management, Denver, 2002.

WHITTINGTON, R. Strategy after modernism: recovering practice. European Management Review, v. 1, n. 1, p. 62-68, mar. 2004.

WHITTINGTON, R. Strategy as practice. Long Range Planning, v. 29, p. 731-735, 1996.

WHITTINGTON, R. The work of strategizing and organizing: for a practice perspective. Strategic Organization, v. 1, n. 1, p. 119-127, 2003. 